\title{
Angiogenesis Factors Associated with New Breast Cancer Cell Line AMJ13 Cultured in Vitro
}

\author{
Ahmed Majeed Al-Shammari ${ }^{*}$, Worod Jawad Kadhim Allak², Mahfoodha Umran², \\ Nahi Y. Yaseen', Ayman Hussien'1 \\ ${ }^{1}$ Experimental Therapy Department, Iraqi Center for Cancer and Medical Genetic Research, Al-Mustansiriyah \\ University, Baghdad, Iraq \\ ${ }^{2}$ Biotechnology Department, Collage of Science, Baghdad University, Baghdad, Iraq \\ Email: *Ahmed.alshammari@iccmgr.org
}

Received 11 August 2015; accepted 27 September 2015; published 30 September 2015

Copyright (C) 2015 by authors and Scientific Research Publishing Inc.

This work is licensed under the Creative Commons Attribution International License (CC BY). http://creativecommons.org/licenses/by/4.0/

(c) () Open Access

\section{Abstract}

Background: AMJ13 is a new breast cancer cell line that has been established from a 70-year-old Iraqi woman with a histological diagnosis of infiltrating ductal carcinoma. It is the first for an Iraqi population. In breast cancer, angiogenesis provides the tumor tissue, which is rapidly proliferated with oxygen and nutrients, removes wastes and increases the opportunity of cancer cells to invade other organs. Methods: The AMJ13 breast cancer cell line was represented at three different passages and incubated for interval times. Microarray panel of 43 different angiogenesis markers was used to scan the supernatant for the factors. ELISA was used to quantify some of the important angiogenesis factors released in the culture medium and to confirm absence of those who was not detected by the antibody array. RT-PCR was used to confirm the gene expression (mRNA) of studied factors. Results: Microarray analysis showed that TIMP1 and two secreted at highest levels compared to the rest of the factors with low presence of endostatin. Other non-detectable factors by microarray examined by ELISA assay that showed highest expression level of VEGF-A were obtained at earliest passage, while the highest levels of FGF-b were obtained at late passage. The VEGF-D secretion was shown low concentrations at all studied passages. There is no detectable level of EGF protein in different passages and times interval tested. There are no significant differences in secretion of sICAM between different passages and incubation periods. Conclusion is that AMJ13 cell line depends on VEGF-A as main angiogenesis factor to induce micro-vessels supported by low levels of VEGF-D for lymphatic vessels formation. AMJ13 cell line depends on FGF as growth factors as in late passages it was shifted to depend mainly on FGF completely. All of this process may be regulated by TGF- $\beta$. TIMP-1 has proangiogentic effect and has feedback talk with TIMP-2. Understanding the angiogenesis process for breast cancer can give us better targets for therapy and

\footnotetext{
${ }^{*}$ Corresponding author.
}

How to cite this paper: Al-Shammari, A.M., Allak, W.J.K., Umran, M., Yaseen, N.Y. and Hussien, A. (2015) Angiogenesis Factors Associated with New Breast Cancer Cell Line AMJ13 Cultured in Vitro. Advances in Breast Cancer Research, 4, 100108. http://dx.doi.org/10.4236/abcr.2015.44011 
more effective treatments.

Keywords

Angiogenesis Factors, Breast Cancer Cell, AMJ13, Tumor Tissue

\section{Introduction}

Angiogenesis is a process of formation of new blood vessels from a pre-existing vasculature [1]. It is important in number of physiological and pathological events [2]. In cancer, angiogenesis provides the tumor tissue which is rapidly proliferated with oxygen and nutrients and remove wastes [3]. Previous studies demonstrate that the tumor growth reaches a steady state at approximately $2-3 \mathrm{~mm}^{2}$ in diameter due to insufficient nutrients and oxygens and the opportunities of tumor distance metastasis are increased with tumor angiogenesis [3] [4]. It is worth mentioning that the tumor cells may start forming new blood vessels by angiogenesis process to continue growing and invade surrounding tissue. Extensive laboratory data suggest that angiogenesis plays an essential role in breast cancer development, invasion, and metastasis [5]. The new blood vessels increased the opportunity of breast cancer cell to enter the blood stream and invade other organs while the tumor that not vascularized still have high death rate until they switch a new angiogenesis [3]. Angiogenesis mechanisms depend on regulation of biological activity and interactions of two cell main types' endothelial and mural cells forming the vessels [6]. Researchers demonstrated that the tumor cells produce pro-angiogenic factors [7] that induce the endothelial cells proliferation to form a new vessel [8]. Angiogenesis process is regulated by the balance between pro- and anti-angiogenesis factors [7]. Vascular endothelial growth factors [VEGF] and its receptors are the key signaling system that regulates proliferation and migration of endothelial cells forming the basis of any vessel [6]. Hypoxia is the main force that initiates angiogenesis and induces VEGF and its receptors via hypoxia inducing factor- $1 \alpha(\mathrm{HIF}-1 \alpha)$. In addition, hypoxia considers an important component that up regulates the expression of different genes associated with various steps of angiogenesis such as VEGF and FGF [9]. Several oncogenes such as K-ras, v-ras, v-yes, fos, and v-raf may induce the up-regulation of angiogenesis factors, cytokines receptors and proteolytic enzymes [3]. Evidence is accumulating that tumor suppressor genes also play a role in the genetic switch of the angiogenesis [10]. Angiogenesis factors can be classified as: 1) soluble growth factors such as VEGF, FGF-1 and FGF-2 which cause endothelial cell growth and differentiation; 2) factors which inhibit proliferation and induce differentiation like TGF- $\beta$ and angiogen; 3 ) extracellular matrix-bound cytokines which regulate angiogenesis such as enodstin and angiostatin. Tumor growth and metastasis can be inhibited by angiogenesis inhibition which was achieved by anti-angiogenesis factors [11]. AMJ13 is a new breast cancer cell line that has been established from an Iraqi breast cancer patient. It is the first for an Iraqi population. The AMJ13 cell line was established from the primary tumor of a 70-year-old Iraqi woman with a histological diagnosis of infiltrating ductal carcinoma. The cells found to be elongated multipolar epithelial-like cells with a population doubling time of 22 hours. The anchorage-independent growth ability test showed that the cells were able to grow in semisolid agarose, confirming their transformed nature. Cytogenetic study of these cells showed chromosomal aberrations with many structural and numerical abnormalities, producing chromosomes of unknown origin called marker chromosomes. Immunocytochemistry showed that the estrogen receptor and the progesterone receptor were not expressed, and a weak positive result was found for HER2/neu gene expression. The cells were positive for BRCA1 and BRCA2, as well as for vimentin [12].

This study aimed to estimate the expression levels of many angiogenesis proteins that are secreted by locally established breast cancer cell line (AMJ13), and to detect the most responsible factors for the angiogenesis process in Iraqi patients to select correct anti-angiogenesis compound in future.

\section{Materials and Methods}

\subsection{Cell Line and Growth Conditions}

The AMJ13 breast cancer cell line was supplied by the Iraqi Center for Cancer and Medical Genetic Research (ICCMGR) Experimental Therapy Department, Cell bank Unit. The cells were represented at three different passages 18, 37 and 60 and gown at (150,000 cell/ml) concentration on RPMI-1640 medium (US biological, 
USA) supplemented with 10\% FBS (Capricorn, Germany) and antibiotics in a humidified atmosphere of 5\% $\mathrm{CO}_{2}$.

\subsection{Human Angiogenesis Antibody Array}

The Membrane-Based Antibody Arrays (Semi-Quantitative, Sandwich-Based) were used as a tool for screening and comparing expression levels of Angiogenesis cytokines, growth factors and soluble receptors.

The Arrays utilize the sandwich immunoassay principle, wherein a panel of capture antibodies were printed on a nitrocellulose membrane solid support.

The supernatants were collected from AMJ13 cells grown at passage 37 after 24 hrs to scan the expression of several factors related with angiogenesis by Antibody Array. The procedure was according to manufacturer protocol, briefly, the samples were incubated for two hrs on the slides. A cocktail of biotinylated Ab were added after washing the membranes. They further incubated for 2 hrs and washed and incubated for one hour with labled streptavidin. Signal detected using (Epichemi3 Darkroom, UVP, USA) and data analyzed using Labworks software (UVP, USA).

\subsection{Quantification of Angiogenesis Factors Release}

To quantify angiogenesis factors release, the culture medium were collected at regular intervals $(6,12,18,24$, 30 and $36 \mathrm{hrs}$ ), and it frozen until further analysis. Angiogenesis factors concentrations were determined by using an Enzyme-linked immunosorbent assay (ELISA) kits according to the manufacturer.s protocol VEGF-A, VEGF-D, FGF-b, EGF (Raybiotech, USA) TGF- $\beta$ and sICAM (IBL, Germany). The GraphPad prism software (GraphPad, San Diego, California, USA) was used to plot the standard curve and calculation the factors concentrations.

\subsection{Reverse Transcription-Polymerase Chain Reaction}

\subsubsection{RNA Extraction}

Total RNA was extracted from AMJ13 cells by (Automated total RNA extraction kit, Anatolia, Turkey) according to the manufacturer's protocol and was quantified by nanodrop.

\subsubsection{Reverse Transcription-Polymerase Chain Reaction}

The expression of mRNAs encoding different polypeptide isoforms of (VEGF-A, VEGF-D, FGF-b, EGF, TGF- $\beta$ and sICAM) were studied by RT-PCR. Specific primers for the (VEGF-A, VEGF-D, FGF-b, EGF, TGF- $\beta$ and sICAM) genes (design of primers was based on published sequence on National Center for Biotechnology Information (NCBI). The $20 \mu \mathrm{l}$ RT-PCR reaction contained $0.27 \mu \mathrm{g}$ of total RNA, specific primer pair, (IDI DNA, USA), and components of the OneStep RT-PCR kit (KAPA Biosystem, USA). Specific detection of TGF- $\beta$ gene was achieved with the following primer pairs: forward 5' TGGTGGAAACCCACAACGAA 3' and reverse 5' GAGCAACACGGGTTCAGGTA 3 ' to detect the TGF- $\beta$ gene and the following primer pairs: forward 5' CTTCAAGCCATCCTGTGTGC 3' and reverse 5' TCTCTCCTATGTGCTGGCCT 3 ' to detect the VEGF-A and the following primer pairs: forward 5' CTTCCCCAAGGATTTCAAGATGA 3' and reverse 5' ATGTCTTCA AACCTATAAAACAGCA 3' to detect the FGF-b in AMJ13 cells. The PCR amplification conditions used for TGF- $\beta$, VEGF-A and FGF-b amplification were as follows: $42^{\circ} \mathrm{C}$ for $5 \mathrm{~min}, 95^{\circ} \mathrm{C}$ followed by 40 cycles of 43 sec: $3 \mathrm{sec}$ at $95^{\circ} \mathrm{C}, 20 \mathrm{sec}$ at $62^{\circ} \mathrm{C}$, and $20 \mathrm{sec}$ at $72^{\circ} \mathrm{C}$. Specific detection of VEGF-D gene was achieved with the following primer pairs: forward 5' TCCCATCGGTCCACTAGGTT 3' and reverse 5' CACACAAGGGGGCTT GAAGA 3' to detect the VEGF-D gene in AMJ13 cells. The PCR amplification conditions used for VEGF-D amplification were as follows: $42^{\circ} \mathrm{C}$ for $5 \mathrm{~min}, 95^{\circ} \mathrm{C}$ followed by 40 cycles of $43 \mathrm{sec}: 3 \mathrm{sec}$ at $95^{\circ} \mathrm{C}, 20 \mathrm{sec}$ at $55.5^{\circ} \mathrm{C}$, and $20 \mathrm{sec}$ at $72^{\circ} \mathrm{C}$. Specific detection of EGF gene was achieved with the following primer pairs: forward 5' CCGCATCTGGGGTCAATCAT 3' and reverse 5' GTGCAGGACCCACACAAGTA 3 ' to detect the EGF gene in AMJ13 cells. The PCR amplification conditions used for TGF- $\beta$ amplification were as follows: $42^{\circ} \mathrm{C}$ for $5 \mathrm{~min}, 95^{\circ} \mathrm{C}$ followed by 40 cycles of $43 \mathrm{sec}: 3 \mathrm{sec}$ at $95^{\circ} \mathrm{C}, 20 \mathrm{sec}$ at $58.5^{\circ} \mathrm{C}$, and $20 \mathrm{sec}$ at $72^{\circ} \mathrm{C}$. The PCR cDNA product was electrophoresed on a $1.4 \%$ agarose gels containing ethidium bromide DNA dye, visualized under UV light, and photographed. Specific amplification was determined by the size of the products on the gel compared to the 100 - 1000 bp DNA ladder (100 bp DNA ladder, KAPA Biosynthesis, USA). 


\subsection{Statistical Analysis}

Statistical analysis of data was performed by using Statistical Package for Social Science (SPSS) version 17 for determination of significant variations by using ANOVA two ways to analysis the data of secretion levels of angiogenesis factors. The differences are considered significant when the probability value is $(<0.05)$.

\section{Results}

\subsection{Scanning for Angiogenesis Factors by Antibody Array}

The experiment showed that the highest level of expressions for angiogenesis factors were TIMP1 and TIMP2. Endostatin factor was secreted in low level comparing to the TIMP1 and TIMP2, while other factors secretions were lower than sensitivity level of the kit. The results are shown in (Figures 1(A)-(C).
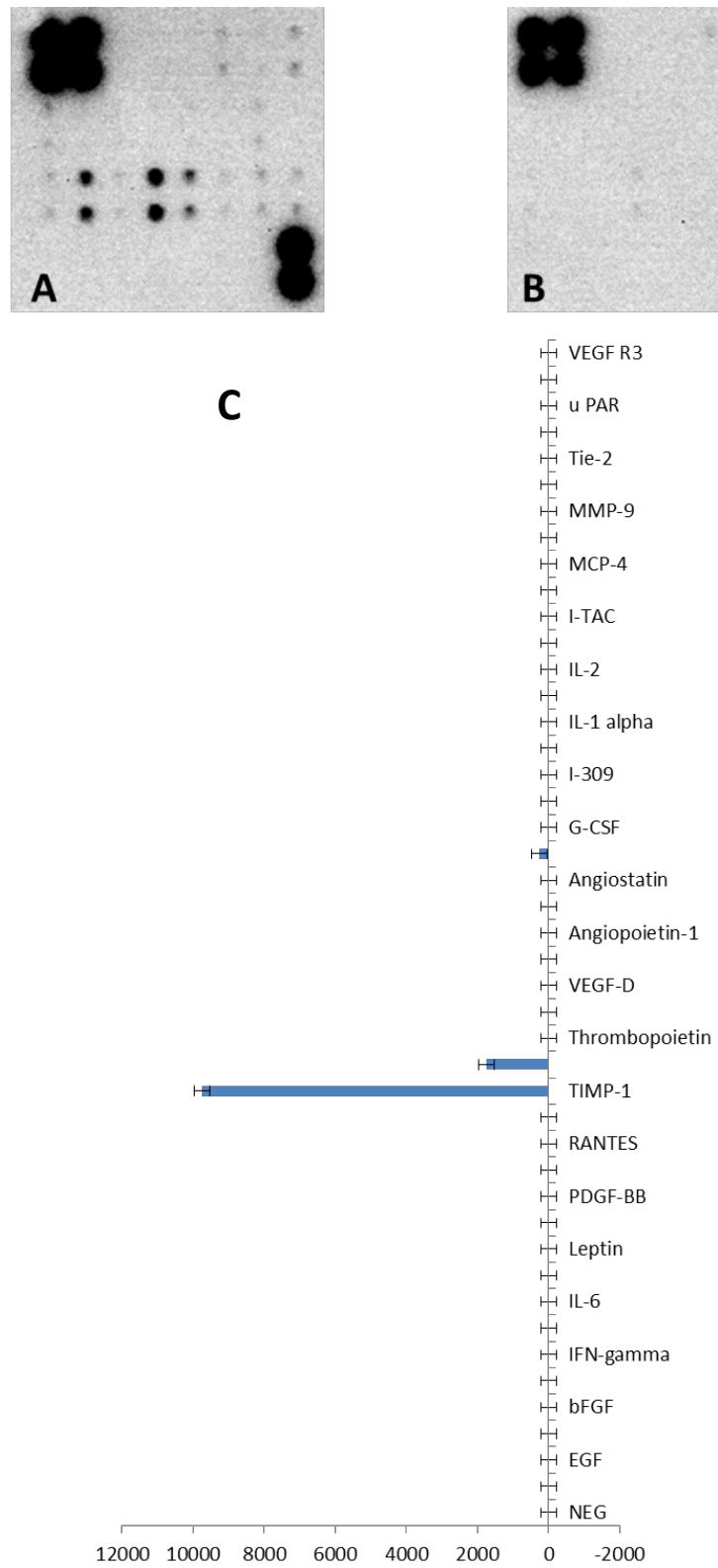

Figure 1. (A) and (B), the membrane with the positive signals. (C), Secretions levels of angiogenesis factors by AMJ13 cultured at passages 37 after 24 hrs incubation at $37^{\circ} \mathrm{C}$ detected by antibody array. 


\subsection{Measuring Angiogenesis Factors by ELISA Assay}

After screening for 43 potential angiogenesis factors and discovered only 3 factors with very high expression, we went now for more sensitive assay to confirm presence some of the most important factors for angiogenesis and breast cancer growth. The measured angiogenesis factors (VEGF-A, VEGF-D, FGF-b, EGF, TGF- $\beta$ and sICAM) to confirm if they secreted by human breast cancer cell line (AMJ13) during different time intervals.

The detection of VEGF-A secretion by AMJ13 cell line was significant. It shown to be increased gradually from low to high levels through time to reach highest peak at 36hrs in the three passages tested. From the (Figure 2), we can notice that early passages (passage 18) were of higher expression when compared to later passages (passages 36 and 60). The higher concentration was detected at passage 18 after 36 hrs of culture, which was $1982 \mathrm{pg} / \mathrm{ml}$.

The expression of VEGF-D was very low and higher concentrations was $36 \mathrm{pg} / \mathrm{ml}$ at passage 60 after $6 \mathrm{hrs}$ and there were no significant differences in secretion levels of the VEGF-D at all interval times and passages measured which indicate that this cancer cell line is not depending on VEGF-D as angiogenesis factors. There is no evidence on EGF protein secretion by the AMJ13 cells at all passages at different intervals. Soluble Intracellular adhesion molecules were detected and its concentrations were increased gradually. There were no significant differences between different passages. The highest secretion levels detected was $1460 \mathrm{pg}$ at passage 60 after 36 hrs.

Fibroblast growth factor were secreted significantly from early passages (18 and 36) at early time (6 hrs) and maintaining good level of expression at all times tested. Surprisingly, the level of expression were changed at passage 60 to show gradual secretion to reach very higher and significant amount especially at 30 and 36 hrs to reach 10,959 and $13,355 \mathrm{pg} / \mathrm{ml}$ respectively.

These results may indicates that the breast cancer cells changed to be depend on FGF-b as a growth factor. The expression levels of FGF-b ranged from $395 \mathrm{pg}$ at passage 60 after 12 hrs to 13,355 pg at passage 60 after 36 hrs.

Transforming growth factor beta (TGF- $\beta$ ) secreted at higher levels as early as 6 hrs of incubation at all three studied passages, while it decreased gradually and significantly depending on incubation times (18, 37, and 60). The concentrations of secreted TGF- $\beta$ ranged from 387 pg at passage 37 after 12 hrs to 2358 pg at passage 37 after 6 hrs (Figure 2).

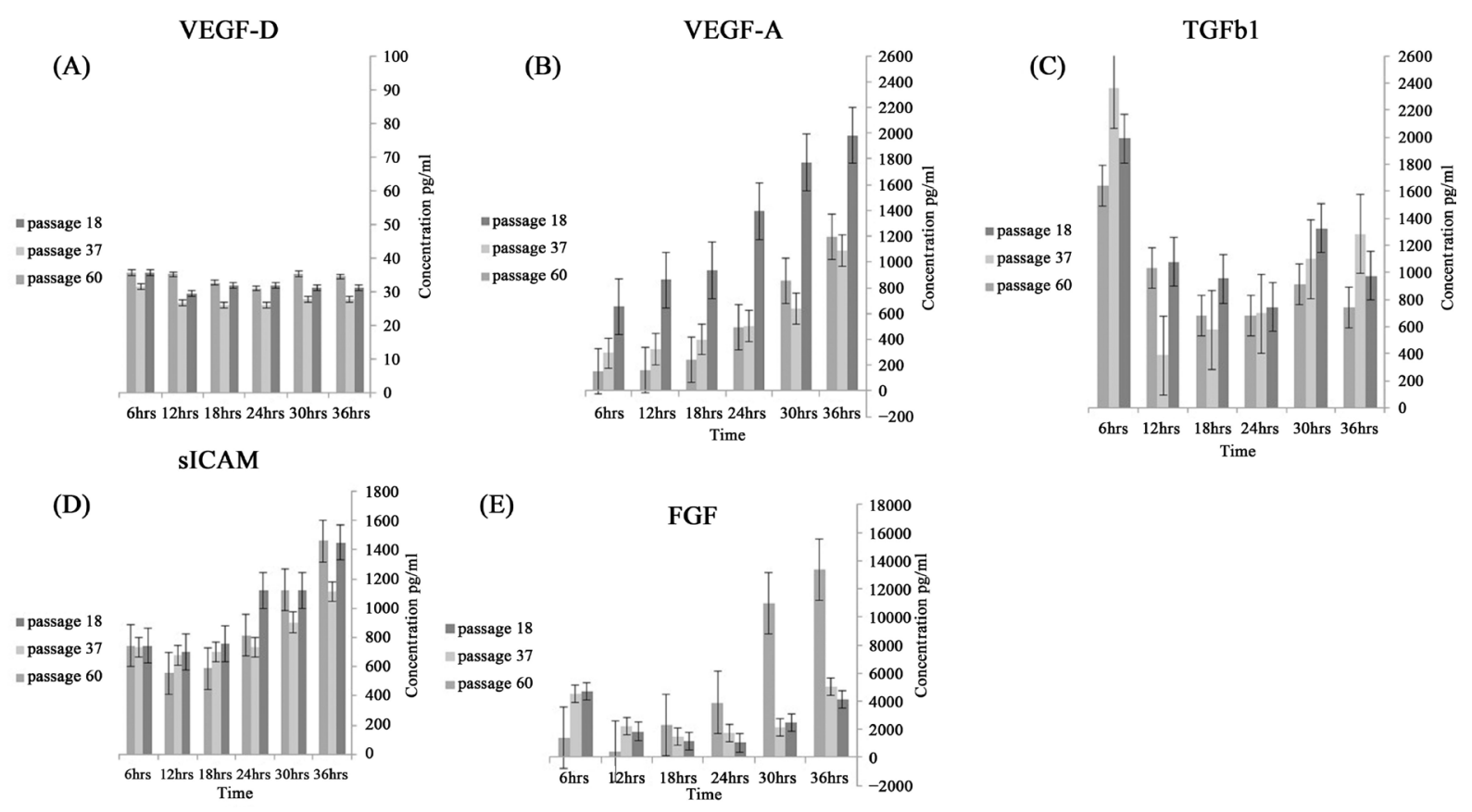

Figure 2. Showing angiogenesis factors concentration secreted by AMJ13 cultured at passages $(18,37$ and 60$)$ during $(6,12$, 18, 24, 30 and 36) hrs at $37^{\circ} \mathrm{C}$ measured by ELISA. (A)-showing VEGF-D, (B)-showing VEGF-A, (C)-showing TGF- $\beta$, (D)-showing sICAM, (E)-showing FGF-b. 


\subsection{Reverse Transcriptase Polymerase Chain Reaction RT-PCR}

The results illustrated in Figure 3 showed appearance of sharp bands in 113 bp, 143 bp and 135 bp and the clear bends in 165 bp and 228 bp in Figures 3(A)-(D) indicate the expression of VEGF-A, TGF- $\beta$, FGF-b, VEGF-D and EGF genes in AMJ13 cells.

\section{Discussion}

Studying angiogenesis factors that associated to the breast cancer is of important value to developing targeting therapies to block cancer proliferation and invasion and even metastasis. Cancer cells secret many factors that activate angiogenesis process to support themselves for nutrients and waste removal [3]. Our experiment is designed to study newly established breast cancer cell line named AMJ13 [12] in regards to its ability to induce angiogenesis by screening its secretions during cells propagations in vitro. This cell line is important as it is first Iraqi breast cancer model and we need to study cancer cells angiogenesis factors and to know which main factor this cancer cells depend on during angiogenesis.

Using microarray technology we screened for the highest levels factors. Tissue inhibitor of metalloproteinases-1 (TIMP-1) was the highest factor that our AMJ13 cell line produce. It is one of new suggested prognostic markers in breast cancer, as a number of studies showed an association between high expression of TIMP-1 protein and a poor prognosis of breast cancer patients, this surprising association is due to a proteolytic activity in cancer cell invasion and metastasis. Tissue inhibitors of metalloproteinases (TIMPs) are a family of endogenous inhibitors associated with the family of enzymes degrades the basement membrane (matrix metalloproteinase MMP) family. Under normal physiologic conditions, the MMPs and TIMPs exist in an exquisite balance and this balance is disrupted during active angiogenesis [5]. However, the recent studies have discovered some other biological functions of TIMP-1 such as growth-stimulating functions, as well as anti-apoptotic and proangiogenetic effects [13]. While the in vitro studies found TIMP-1 did not affect the proliferation of the endothelial cells (ECs) and tumor cells, suggesting that the TIMP-1 was not cytotoxic protein [14].

The second factor secreted by AMJ13 is the other member of TIMPs family (Tissue inhibitors of metalloproteinase-2 TIMP-2) that is associated with angiogenesis, invasion, and metastasis. TIMP-2 found to inhibit angiogenesis in vivo and inhibits endothelial cells proliferation and migration in vitro through MMP-dependent mechanisms and MMP-independent mechanisms mediated by endothelial cells proteolysis [15]. This factor may play as feedback to control the other angiogenesis factor and for that, its presence was in low quantities in compare to TIMP-1. The role of TIMP-2 was controversial in breast cancer due to the controversial results in which high TIMP-2 expression was associated either with experienced low cancer recurrence/progression or with a poor prognosis confirming the activating or inhibitory role of TIMP-2 [16].

To establish AMJ13 mechanism for angiogenesis we conducted quantitative study for some of the most important factors that may be associated with angiogenesis and cell growth. We quantitate the secreted VEGF-A factor during first $36 \mathrm{~h}$ of the cells propagation. We noticed elevated pattern which can link the VEGF-A secretion levels to several changes in the microenvironment such as hypoxic and/or nutrients deficiency in the culture medium as a variation in physiological conditions [17] that might stimulate the secretion of angiogenic factors to

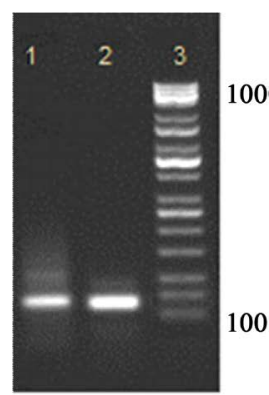

(A)

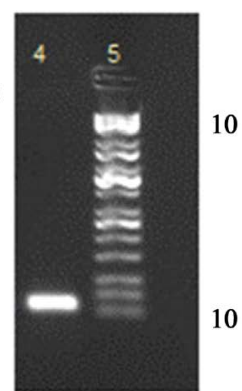

(B)

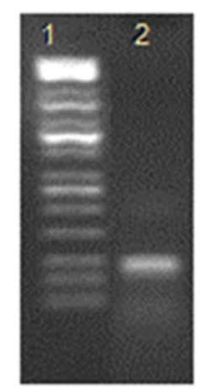

(C)

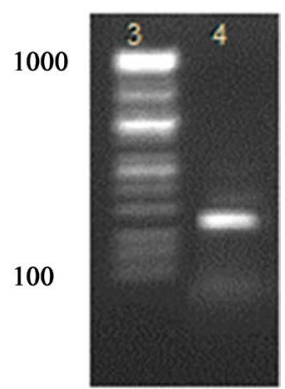

(D)

Figure 3. Agarose Gel electrophoresis of RT-PCR products of (A) Lane one and 2 are VEGF-A, FGF-b with size of 143 bp and 135 bp respectively. (B) TGF- $\beta$ genes with size of $113 \mathrm{bp}$. Staining with ethidium bromide and visualized under U.V light, Lane 3 and 5 DNA ladder (100 - 1000). (C) VEGF-D gene with size of 165 bp (D) EGF with PCR product size of 228 bp. Lane 1 and 3 DNA ladder (100 - 1000); Lanes 2 VEGF-D Lanes 4 EGF. 
increase blood supply in response to nutrient deprivation and hypoxia [18]. Saponaro et al. [19] demonstrate that the VEGF-A expression in BRCA1-2 carrier breast cancer tissues was higher than that in BRCAX breast cancer tissues. This confirms what we have in AMJ13 the cell line under investigation which is BRCA1 positive [12]. Furthermore, in both BRCA1-2 carriers and BRCAX the VEGF-A expression was higher than the sporadic group. VEGF-A can be stimulated by other conditions as hypoxia and TGF- $\beta 1$ [20] and Platelet-derived growth factor (PDGF) [21]. Moreover, we noticed that VEGF-A levels were higher compared to later passages, which was explained by the less need for the factor because culture media is providing sufficient nutrients and less need for angiogenesis in vitro.

The secreted levels of VEGF-D by our AMJ13 breast cancer cells were very low in all times tested. This factor showed significant variations in 105 breast cancer patients and it may be completely absent in some breast tumors, as reported by Nakamura et al. [22]. Formation of lymphatics within tumors is activated by VEGF-D Stimulation, which also promotes tumor angiogenesis [23]. We suggest that AMJ13 needs less lymphatic vessels which explain the low level of VEGF-D but need higher angiogenesis to deliver nutrients and oxygenation which explain the higher levels for VEGF-A.

Epidermal growth factor is one of the important growth factors and the investigation showed no evidence on EGF protein secretion by the grown cells at all passages at different intervals. Many other human negative estrogen receptor breast cancer cell lines (BT20 and MDA MB 231 cells) showed low or no expression levels of EGF [24]. These data confirm our results, whereas AMJ13 cells are negative estrogen receptor cell line [12]. However, not all estrogen receptor positive cell lines express the EGF as there is no EGF mRNA in MCF 7 cells [24]. Secretions of EGF was observed in (31\%) of primary tumors only [25]. Mori et al. [26] suggested that MCF-7 human breast cancer cell line synthesize and secrete a polypeptide immunologically related to human EGF into the culture medium. The molecular weight of this poly peptide was similar to that of EGF from human urine. However, in enzyme immunoassay system the dose-response curve of MCF-7 EGF did not show good parallelism with that of standard human EGF. These data may explain why the results of EGF obtained by ELISA differ from that obtained by RT-PCR.

The obtained results from quantitative ELISA assay showed significant increasing in sICAM concentration depending on incubation time and progression of passages. The high expression rate of sICAM-1 in breast cancer patients is associated with tumors at advanced stages and with those with the estrogen receptor negative phenotype [27] and the level of sICAM-1 in the serum of women with breast cancer was significantly higher than that observed in the serum of healthy women. They also found significant differences in sICAM expression between women with metastases to the axillary lymph nodes and women with no metastasis [28]. sICAM-1 concentrations increased in serum of breast cancer patients, and their levels seem to be related to poorer therapy response and prognosis [29]. Angiogenesis and neovascularization could be stimulated by sICAM-1 and promote tumor growth and cell migration [30]. Furthermore, sICAM-I may be involved in the progression of metastasis in certain malignancies [31]. Therefore, sICAM may be considered an important target in breast cancer therapy.

In AMJ13, we can notice shifting in growth factors that regulate cell growth, the increasing of FGF-b secretion levels at the late passage (60) and absence in the EGF secretion can give this impression, whereas FGF-b plays an important role in cell proliferation, differentiation and migration [32]. FGF-b is a critical growth factor in normal and malignant cell proliferation and tumor-associated angiogenesis and there is a significant correlation between the presence of FGF-b in cancer cells and advanced tumor stage [33].

We found that TGF- $\beta$ peaks immediately as highest concentration recorded at all passages tested were as early as six hours after plating. The expression of TGF- $\beta$ by breast cancer cells may be influenced by other factors such as estrogen receptor status [34]. Buck and Cornelius [35] demonstrate that the estrogen receptor plays an essential role in the expression of TGF- $\beta$ signaling. TGF-beta expression is upregulated in breast cancer and it correlates with poor prognosis [36]. TGF- $\beta$ binds Anaplastic lymphoma kinase5 (ALK5) receptor on endothelial cells resulting in vessel maturation and angiogenic resolution by Smad2/3 activation pathway. Increased expression of TGF- $\beta$ correlates with increased microvessel density and with poor prognosis in various tumor types, such as breast cancer and non-small cell lung carcinoma [37]. We explain the immediate peak for this factor by its regulatory effect on other growth factors. For example, TGF- $\beta$ regulates the reactive stroma microenvironment associated with most carcinomas, mediates expression of many stromal derived factors important for tumor progression, including FGF-2 [36], and stimulates VEGF-A [20]. Our conclusion is that AMJ13 cell line depends on VEGF-A as main angiogenesis factor to induce micro-vessels supported by low levels of VEGF-D for 
lymphatic vessels formation. AMJ13 cell line depends on FGF as growth factors as in late passages it was shifted to depend mainly on FGF completely. All of this process may regulated by TGF- $\beta$. TIMP-1 has proangiogenic effect and has feedback talk with TIMP-2. Understanding the angiogenesis process for breast cancer can give us better targets for therapy and more effective treatments.

\section{References}

[1] US Department of Agriculture Animal and Plant Health Services. Info Sheet: Bovine Leukosis Virus (BLV) in U.S. Beef Cattle. February 1999.

[2] Tonini, T., Rossi, F. and Claudio, P.P. (2003) Molecular Basis of Angiogenesis and Cancer. Oncogene, 22, $6549-6556$. http://dx.doi.org/10.1038/sj.onc.1206816

[3] Liekens, S., De Clercq, E. and Neyts, J. (2001) Angiogenesis: Regulators and Clinical Applications. Biochemical Pharmacology, 61, 253-270. http://dx.doi.org/10.1016/S0006-2952(00)00529-3

[4] Nishida, N., et al. (2006) Angiogenesis in Cancer. Vascular Health and Risk Management, 2, 213-219. http://dx.doi.org/10.2147/vhrm.2006.2.3.213

[5] Schneider, B.P. and Miller, K.D. (2005) Angiogenesis of Breast Cancer. Journal of Clinical Oncology, 23, $1782-1790$. http://dx.doi.org/10.1200/JCO.2005.12.017

[6] Karamysheva, A.F. (2008) Mechanisms of Angiogenesis. Biochemistry (Moscow), 73, 751-762. http://dx.doi.org/10.1134/S0006297908070031

[7] Carmeliet, P. (2000) Mechanisms of Angiogenesis and Arteriogenesis. Nature Medicine, 6, 389-395. http://dx.doi.org/10.1038/74651

[8] Jain, R.K. (2003) Molecular Regulation of Vessel Maturation. Nature Medicine, 9, 685-693. http://dx.doi.org/10.1038/nm0603-685

[9] Pugh, C.W. and Ratcliffe, P.J. (2003) Regulation of Angiogenesis by Hypoxia: Role of the HIF System. Nature Medicine, 9, 677-684. http://dx.doi.org/10.1038/nm0603-677

[10] Van Meir, E.G., et al. (1994) Release of an Inhibitor of Angiogenesis upon Induction of Wild Type p53 Expression in Glioblastoma Cells. Nature Genetics, 8, 171-176. http://dx.doi.org/10.1038/ng1094-171

[11] Wu, H.-C., Huang, C.-T. and Chang, D.-K. (2008) Anti-Angiogenic Therapeutic Drugs for Treatment of Human Cancer. Journal of Cancer Molecules, 4, 37-45.

[12] Al-Shammari, A.M., Alshami, M., Umran, M., et al. (2015) Establishment and Characterization of a Receptor-Negative, Hormone-Nonresponsive Breast Cancer Cell Line from an Iraqi Patient. Breast Cancer: Targets and Therapy, 7, 223230. http://dx.doi.org/10.2147/BCTT.S74509

[13] Würtz, S.Ø., et al. (2005) Tissue Inhibitor of Metalloproteinases-1 in Breast Cancer. Endocrine-Related Cancer, 12, 215-227. http://dx.doi.org/10.1677/erc.1.00719

[14] Ikenaka, Y., Yoshiji, H., Kuriyama, S., et al. (2003) Tissue Inhibitor of Metalloproteinases-1 (TIMP-1) Inhibits Tumor Growth and Angiogenesis in the TIMP-1 Transgenic Mouse Model. International Journal of Cancer, 105, 340-346. http://dx.doi.org/10.1002/ijc.11094

[15] Bourboulia, D., Jensen-Taubman, S., Rittler, M.R., et al. (2011) Endogenous Angiogenesis Inhibitor Blocks Tumor Growth via Direct and Indirect Effects on Tumor Microenvironment. The American Journal of Pathology, 179, 25892600. http://dx.doi.org/10.1016/j.ajpath.2011.07.035

[16] Têtu, B., Brisson, J., Wang, C., et al. (2006) The Influence of MMP-14, TIMP-2 and MMP-2 Expression on Breast Cancer Prognosis. Breast Cancer Research, 8, R28. http://dx.doi.org/10.1186/bcr1503

[17] Elias, A.P. and Dias, S. (2008) Microenvironment Changes (in pH) Affect VEGF Alternative Splicing. Cancer Microenvironment, 1, 131-139. http://dx.doi.org/10.1007/s12307-008-0013-4

[18] Marjon, P.L., Bobrovnikova-Marjon, E.V. and Abcouwer, S.F. (2004) Expression of the Pro-Angiogenic Factors Vascular Endothelial Growth Factor and Interleukin-8/CXCL8 by Human Breast Carcinomas Is Responsive to Nutrient Deprivation and Endoplasmic Reticulum Stress. Molecular Cancer, 3, 5670-5674.

[19] Saponaro, C., Malfettone, A., Ranieri, G., et al. (2013) VEGF, HIF-1alpha Expression and MVD as an Angiogenic Network in Familial Breast Cancer. PLoS ONE, 8, e53070. http://dx.doi.org/10.1371/journal.pone.0053070

[20] Darrington, E., Zhong, M., Vo, B.-H., et al. (2012) Vascular Endothelial Growth Factor A, Secreted in Response to Transforming Growth Factor- $\beta 1$ under Hypoxic Conditions, Induces Autocrine Effects on Migration of Prostate Cancer Cells. Asian Journal of Andrology, 14, 745-751. http://dx.doi.org/10.1038/aja.2011.197

[21] Matei, D., Kelich, S., Cao, L.Y., et al. (2007) PDGF BB Induces VEGF Secretion in Ovarian Cancer. Cancer Biology \& Therapy, 6, 1951- 1959. http://dx.doi.org/10.4161/cbt.6.12.4976 
[22] Nakamura, Y., Yasuoka, H., Tsujimoto, M., et al. (2003) Prognostic Significance of Vascular Endothelial Growth Factor D in Breast Carcinoma with Long-Term Follow-Up. Clinical Cancer Research, 9, 716-721.

[23] Stacker, S.A., Caesar, C., Baldwin, M.E., Thornton, G.E., et al. (2001) VEGF-D Promotes the Metastatic Spread of Tumor Cells via the Lymphatics. Nature Medicine, 7, 186-191. http://dx.doi.org/10.1038/84635

[24] Murphy, L.C. and Dotzlaw, H. (1989) Endogenous Growth Factor Expression in T-47D, Human Breast Cancer Cells, Associated with Reduced Sensitivity to Antiproliferative Effects of Progestins and Antiestrogens. Cancer Research, 49, 599-604.

[25] O’sullivan, C., Lewis, C.E., Harris, A.L., et al. (1993) Secretion of Epidermal Growth Factor by Macrophages Associated with Breast Carcinoma. The Lancet, 342, 148-149. http://dx.doi.org/10.1016/0140-6736(93)91348-P

[26] Mori, K., Kurobe, M., Furukawa, S., et al. (1986) Human Breast Cancer Cells Synthesize and Secrete an EGF-Like Immunoreactive Factor in Culture. Biochemical and Biophysical Research Communications, 136, 300-305. http://dx.doi.org/10.1016/0006-291X(86)90909-5

[27] El-Sayed, L.H.G., Fadali, G., Saad, A., Hafez, E.S. and Shaaban, S. (2010) Expression of MAGE-A Genes and Soluble ICAM-1 in Egyptian Breast Cancer Patients: Possible Prognostic Impact. Journal of the Medical Research Institute, 31, 7-18.

[28] Thielemann, A., Baszczuk, A., Kopczyński, Z., et al. (2014) The Clinical Usefulness of Assessing the Concentration of Cell Adhesion Molecules sVCAM-1 and sICAM-1 in the Serum of Women with Primary Breast Cancer. Wspótczesna Onkologia, 4, 252-259. http://dx.doi.org/10.5114/wo.2014.43492

[29] Eggeman, H., et al. (2011) Influence of a Dose-Dense Adjuvant Chemotherapy on sVCAM-1/sICAM-1 Serum Levels in Breast Cancer Patients with 1-3 Positive Lymph Nodes. Anticancer Research, 31, 2617-2622.

[30] Touvier, M., Fezeu, L., Ahluwalia, N., et al. (2013) Association between Prediagnostic Biomarkers of Inflammation and Endothelial Function and Cancer Risk: A Nested Case-Control Study. American Journal of Epidemiology, 177, 313. http://dx.doi.org/10.1093/aje/kws359

[31] Lai, L., Kadory, S., Cornell, C., et al. (1993) Possible Regulation of Soluble Icam-1 Levels by Interleukin-1 in a Sub-Set of Breast Cysts. International Journal of Cancer, 55, 586-589. http://dx.doi.org/10.1002/ijc.2910550412

[32] Cross, M.J. and Claesson-Welsh, L. (2001) FGF and VEGF Function in Angiogenesis: Signalling Pathways, Biological Responses and Therapeutic Inhibition. Trends in Pharmacological Sciences, 22, 201-207. http://dx.doi.org/10.1016/S0165-6147(00)01676-X

[33] Sahni, A., Simpson-Haidaris, P.J., Sahni, S.K., et al. (2008) Fibrinogen Synthesized by Cancer Cells Augments the Proliferative Effect of Fibroblast Growth Factor-2 (FGF-2). Journal of Thrombosis and Haemostasis, 6, 176-183. http://dx.doi.org/10.1111/j.1538-7836.2007.02808.x

[34] MacCallum, J., Bartlett, J.M.S., Thompson, A.M., et al. (1994) Expression of Transforming Growth Factor Beta mRNA Isoforms in Human Breast Cancer. British Journal of Cancer, 69, 1006-1009. http://dx.doi.org/10.1038/bjc.1994.197

[35] Buck, M.B. and Knabbe, C. (2006) TGF-Beta Signaling in Breast Cancer. Annals of the New York Academy of Sciences, 1089, 119-126. http://dx.doi.org/10.1196/annals.1386.024

[36] Pardali, E. and ten Dijke, P. (2008) Transforming Growth Factor-Beta Signaling and Tumor Angiogenesis. Frontiers in Bioscience (Landmark Edition), 14, 4848-4861. http://dx.doi.org/10.2741/3573

[37] Lebrun, J.-J. (2012) The Dual Role of TGF in Human Cancer: From Tumor Suppression to Cancer Metastasis. ISRN Molecular Biology, 2012, Article ID: 381428. 